\title{
Hybrid Neural Network Bankruptcy Prediction: An Integration of Financial Ratios, Intellectual Capital Ratios, MDA, and Neural Network Learning
}

\author{
Wen-Kuei Hsieh $^{1}$ Shang-Ming Liu ${ }^{2}$ Sung-Yi Hsieh ${ }^{3}$ \\ ${ }^{1}$ Department of Finance, De Lin Institute of Technology, Taipei 236, Taiwan E-mail: wkhsieh@dlit.edu.tw \\ ${ }^{2}$ Department of Finance, De Lin Institute of Technology, Taipei 236, Taiwan \\ ${ }^{3}$ Department of Finance, De Lin Institute of Technology, Taipei 236, Taiwan
}

\begin{abstract}
One purpose of this paper is to propose the hybrid neural network models for bankruptcy prediction. The proposed hybrid neural network models are, respectively, a MDA model integrated with financial ratios, a MDA model integrated with financial ratios and intellectual capital ratios, a MDA-assisted neural network model integrated with financial ratios, and a MDA-assisted neural network model integrated with financial ratios and intellectual capital ratios. The performance of the hybrid neural network model is compared with MDA model integrated with financial ratios as a benchmark. Empirical results using Taiwan bankruptcy data show that hybrid neural network models are very promising ones in terms of accuracy and adaptability.
\end{abstract}

Keywords: Bankruptcy prediction; Neural network; Hybrid neural network

\section{Motivation and Literature review}

The importance of computational intelligence to economics and finance is quite evidentiary $[3,4]$. Areas of business classification include bankruptcy prediction, accounting method choice, audit opinion decisions, credit rating, and bank loan classification. Classification refers to separating distinct sets of observations and allocating new observations into the previously defined groups. Bankruptcy prediction has been a major research issue in accounting and finance for years. Neural networks have been performed well in business classifications including bankruptcy prediction. There exist studies in bankruptcy prediction using statistical approaches $[1,2,6,7,8]$ and computational intelligence approaches $[5,9,11,12,14]$. MDA has been the dominant method in failure prediction. Neural networks also have been applied to classification problems such as management forecasting, bond rating, stock price prediction, interest rate prediction, and extraction of accounting knowledge.
Researches proposed hybrid neural network models and proved with higher predictive performance $[10,13]$. This study proposes four kinds of hybrid bankruptcy prediction models: (1) a MDA model integrated with financial ratios, (2) a MDA model integrated with financial ratios and intellectual capital ratios, (3) a MDA-assisted neural network model integrated with financial ratios, and (4) a MDA-assisted neural network model integrated with financial ratios and intellectual capital ratios. Other purposes of this study are (1) to explore the accuracy of four forecasting models in predicting bankruptcy; (2) to compare the prediction capabilities between model 1 and model 2 , as well as the prediction capabilities between model 3 and model 4, i.e. with or without intellectual capital ratios; (3) to evaluate the prediction capabilities between model 1 - 2 and model $3 \cdot 4$, i.e. with or without two stages hybrid bankruptcy prediction models.

A MDA-assisted neural network model is a neural network model operating with input variables selected by MDA method. The experimental samples in this study consist of bankruptcy cases reported in R.O.C. from 2002 through 2005. We employ 75 enterprises as experimental samples. The 80 financial ratios and 12 intellectual capital ratios are used as input variables.

\section{Classification models for bankruptcy prediction}

\subsection{Multivariate discriminating analysis}

Multivariate discriminating analysis (MDA) is a statistical method commonly used in classification. It estimates the linear function which can most effectively classify the objects as follows:

$$
\mathrm{D}=\mathrm{B}_{0}+\mathrm{B}_{1} \mathrm{X}_{1}+\mathrm{B}_{2} \mathrm{X}_{2}+\ldots . .+\mathrm{B}_{\mathrm{i}} \mathrm{X}_{\mathrm{i}}
$$

Where $\mathrm{D}$ is a discriminate score, $\mathrm{B}_{0}$ is an estimated constant, $\mathrm{B}_{\mathrm{i}}$ are the estimated coefficients, and $\mathrm{X}_{\mathrm{i}}$ are the variables.

\subsection{MDA-assisted neural network}


The intention underlying the MDA-assisted neural network model is that MDA method is used as preprocessing mechanism for selecting important input variables which will be used in the neural network model.

\subsection{Neural network}

Since our problem is constructed of continuous input variables and discrete output variables, we can use the multilayer feed-forward network. By using Functional approximation capability of neural network theorem and Kolmogorov's mapping neural network existence theorem, we define the hidden layers by determining how many layers are necessary and how many nodes are optimal in the hidden layer [7]. The functional approximation theorem means that the one hidden layer architecture could solve all kinds of problem, if the input variables are normalized from zero to one. Kolmogorov's theorem suggests that the maximum number of nodes in a hidden layer should be restricted to $2 n+1$, where $\mathrm{n}$ is the number of input nodes.

Multilayer feed-forward networks use the generalized delta rule for weight updating. The weight updating rule has two coefficients of learning rate and momentum. This model is known as slop learning. We vary learning rate from 0.04 to 0.07 and fix the momentum at 0.5 . The weight updating rule used in our experiment is as follows:

$$
\begin{aligned}
& \Delta \mathrm{W}_{\mathrm{ji}}(\mathrm{n}+1)=\eta\left(\delta_{\mathrm{pj}} O \mathrm{p}_{\mathrm{j}}\right)+\Delta \mathrm{W}_{\mathrm{ji}}(\mathrm{n}) \\
& \Delta \Theta_{\mathrm{j}}(\mathrm{n}+1)=\eta \delta_{\mathrm{pj}}+\alpha \Delta \Theta_{\mathrm{j}}(\mathrm{n})
\end{aligned}
$$

Where $\Delta \mathrm{W}_{\mathrm{ji}}(\mathrm{n})$ is the derivative of weight from mode I to $\mathrm{J}$ at time $\mathrm{n}, \Delta \Theta \mathrm{j}(\mathrm{n})$ is the derivative of the bias of node $\mathrm{j}$ at time $\mathrm{n}, \eta$ is the learning rate, $\alpha$ is momentum, $\delta_{\mathrm{pj}}$ is the delta of node $\mathrm{j}$ and pattern $\mathrm{p}$, and $O \mathrm{p}_{\mathrm{j}}$ is the output node $\mathrm{j}$ and pattern $\mathrm{p}$.

As to transfer function, since the output variable ranges from 0 to 1 , and for the purpose of smooth the effect of input variables, we, therefore, employ the sigmoid function in back-propagation algorithms and apply a commercialized package called "Neural Solution 4" for this study.

\section{Research data and modeling}

\subsection{Research data}

The experimental samples in this study consist of bankruptcy cases reported in R.O.C. from 2002 through 2005. They are selected from the bankruptcy companies listed in the Taiwan Stock Exchange. We define the state of bankruptcy as follows:

- The firms are under the process of corporate clearance.

- The firms closed business.
- The firms have had losses for the consecutive three years and are under legal control.

- The firms terminated to be listed by the Taiwan Stock Exchange.

By using the above definition of bankruptcy, we collect 25 bankruptcy enterprises. A failed firm is matched with two non-failed firms. Therefore, 75 firms in total are selected as experimental samples. The initial 10 categories of financial ratios are selected for prediction model. Hence, there are 80 seasonal financial ratios, 10 (categories) times 4 (seasons) times 2 (years), which used as input variables. The list of financial ratios is shown in table 1. In addition to financial ratios, there are 12 intellectual capital ratios, 6 (categories) times 2 (years), which also used as input variables. The initial 6 categories of intellectual capital ratios are listed in Table 2.

Table 1

A list of 10 financial variables

\begin{tabular}{|l|l|}
\hline Section & Financial ratio \\
\hline Profitability & Operating income margin \\
\cline { 2 - 2 } & Gross profit margin \\
\cline { 2 - 2 } Sinancial & Other income-net ratio \\
\hline \multirow{5}{*}{$\begin{array}{l}\text { Structure } \\
\end{array}$} & Debt ratio \\
\cline { 2 - 2 } & Time interest earned \\
\cline { 2 - 2 } & Quit ratio \\
\cline { 2 - 2 } & Working capital ration \\
\cline { 2 - 2 } $\begin{array}{l}\text { Working } \\
\text { effectiveness }\end{array}$ & Long term funds to fixed assets \\
\cline { 2 - 2 } & Inventory turnover \\
\hline
\end{tabular}

Table 2

A list of 6 intellectual capital variables

\begin{tabular}{|l|l|}
\hline Section & Intellectual capital ratio \\
\hline $\begin{array}{l}\text { Structure } \\
\text { capital }\end{array}$ & Times of changing accountant \\
\cline { 2 - 2 } & $\begin{array}{l}\text { Times of changing financial } \\
\text { prediction }\end{array}$ \\
\cline { 2 - 2 } & Employees ratio \\
\hline $\begin{array}{l}\text { Creativity } \\
\text { capital }\end{array}$ & Research and development \\
\hline $\begin{array}{l}\text { Process } \\
\text { capital }\end{array}$ & Management expense \\
\cline { 2 - 2 } & Enterprise ages \\
\hline
\end{tabular}

\subsection{Modeling}

\section{Model 1: MDA model integrated with financial ratios}

A list of financial ratios, Table 3 , is selected as important variables for Model 1.

\section{Model 2: MDA model integrated with financial}


ratios and intellectual capital ratios

A list of financial ratios and intellectual capital ratio, Table 4, is selected as important variables for Model 2.

Table 3

A list of financial variables

\begin{tabular}{|l|l|}
\hline Quarters & Financial ratio \\
\hline Ex $5^{\text {th }}$ & Long term funds to fixed assets \\
\hline Ex $3^{\text {rd }}$ & Gross profit margin \\
\hline Ex $4^{\text {th }}$ & Gross profit margin \\
\hline Ex $6^{\text {th }}$ & Gross profit margin \\
\hline
\end{tabular}

Table 4

A list of financial variables and intellectual capital variable

\begin{tabular}{|l|l|}
\hline $\begin{array}{l}\text { Quarters } \\
\text { Year }\end{array}$ & $\begin{array}{l}\text { Financial ratio/ Intellectual } \\
\text { Capital ratio }\end{array}$ \\
\hline Ex $5^{\text {th }} \mathrm{Q}$ & Long term funds to fixed assets \\
\hline Ex $3^{\text {rd }} \mathrm{Q}$ & Gross profit margin \\
\hline Ex $4^{\text {th }} \mathrm{Q}$ & Gross profit margin \\
\hline Ex 1 year & Management expense \\
\hline Ex $6^{\text {th }}$ & Gross profit margin \\
\hline
\end{tabular}

\section{Model 3: MDA-assisted neural network model} integrated with financial ratios

A list of financial ratios, Table 5, is selected by MDA as important variables for Model 3. Therefore, the four financial variables are placed in the input layer for neural network model. A list of parameters, Table 6, is selected as hidden layers and learning rates for neural network architectures. With one output neuron is placed in the output layer. We employ the value of root mean square error, RMSE, as a comparing standard.

Table 5

A list of financial variables

\begin{tabular}{|l|l|}
\hline Quarters & Financial ratio \\
\hline Ex $5^{\text {th }}$ & Long term funds to fixed assets \\
\hline Ex $3^{\text {rd }}$ & Gross profit margin \\
\hline Ex $4^{\text {th }}$ & Gross profit margin \\
\hline Ex $6^{\text {th }}$ & Gross profit margin \\
\hline
\end{tabular}

Table 6

A list of parameters for neural network architectures

\begin{tabular}{|l|llll|}
\hline Hidden neurons & \multicolumn{5}{|l|}{ Learning rates } \\
\hline 8 & 0.04 & 0.05 & 0.06 & 0.07 \\
\hline 9 & 0.04 & 0.05 & 0.06 & 0.07 \\
\hline 10 & 0.04 & 0.05 & 0.06 & 0.07 \\
\hline 11 & 0.04 & 0.05 & 0.06 & 0.07 \\
\hline 12 & 0.04 & 0.05 & 0.06 & 0.07 \\
\hline
\end{tabular}

Model 4: MDA-assisted neural network model

\section{integrated with financial ratios and intellectual capital ratios}

A list of financial ratios and intellectual capital ratio, Table 7, is selected by MDA as important variables for Model 4. Therefore, the four financial variables and one intellectual capital variable are placed in the input layer for neural network model. A list of parameters, Table 8 , is selected as hidden layers and learning rates for neural network architectures. Finally, one output neuron is placed in the output layer. We employ the value of root mean square error, RMSE, as a comparing standard.

Table7

A list of financial variables and intellectual capital variable

\begin{tabular}{|l|l|}
\hline $\begin{array}{l}\text { Quarters } \\
\text { Year }\end{array}$ & $\begin{array}{l}\text { Financial ratio/ Intellectual } \\
\text { Capital ratio }\end{array}$ \\
\hline Ex $5^{\text {th }} \mathrm{Q}$ & Long term funds to fixed assets \\
\hline Ex 3 ${ }^{\text {rd }} \mathrm{Q}$ & Gross profit margin \\
\hline Ex ${ }^{\text {th }} \mathrm{Q}$ & Gross profit margin \\
\hline Ex 1 year & Management expense \\
\hline Ex 6 & Gross profit margin \\
\hline
\end{tabular}

Table8

A list of parameters for neural network architectures \begin{tabular}{|l|l|}
\hline Hidden neurons & Learning rates \\
\hline
\end{tabular}

\begin{tabular}{|l|llll|}
\hline 12 & 0.04 & 0.05 & 0.06 & 0.07 \\
\hline 13 & 0.04 & 0.05 & 0.06 & 0.07 \\
\hline 14 & 0.04 & 0.05 & 0.06 & 0.07 \\
\hline 15 & 0.04 & 0.05 & 0.06 & 0.07 \\
\hline 16 & 0.04 & 0.05 & 0.06 & 0.07 \\
\hline
\end{tabular}

\section{Empirical results}

For Model 3, the neural network structure $\{4-9-1\}$, with the learning rate of 0.05 , performs the best. For Model 4, the neural network structure $\{5-12-1\}$, with the learning rate of 0.05 , performs the best.

The prediction accuracy by model 1 , MDA model integrated with financial ratios, is $86 \%$. The prediction accuracy by model 2, MDA model integrated with financial ratios and intellectual capital ratio, is $88 \%$.

The prediction accuracy by model 3, MDA-assisted neural network model integrated with financial ratios, is $88 \%$. The prediction accuracy by model 4, MDA-assisted neural network model integrated with financial rations and intellectual capital ratio, is $89 \%$. Those are prediction capability differences between with and without intellectual capital ratios, and prediction capability differences between with and without two stages hybrid bankruptcy prediction models. A list of prediction accuracies for classification models is presented in Table 9. 
Table 9

Prediction accuracies of classification models

\begin{tabular}{|l|l|l|}
\hline Models & Descriptions & accuracies \\
\hline I & $\begin{array}{l}\text { MDA model integrated } \\
\text { with financial ratios }\end{array}$ & $86 \%$ \\
\hline II & $\begin{array}{l}\text { MDA model integrated } \\
\text { with financial ratios } \\
\text { and intellectual capital } \\
\text { ratios }\end{array}$ & $88 \%$ \\
\hline III & $\begin{array}{l}\text { MDA-assisted neural } \\
\text { network model } \\
\text { integrated with } \\
\text { financial ratios }\end{array}$ & $88 \%$ \\
\hline IV & $\begin{array}{l}\text { MDA-assisted neural } \\
\text { network model } \\
\text { integrated with } \\
\text { financial rations and } \\
\text { intellectual capital } \\
\text { ratios }\end{array}$ & $89 \%$ \\
\hline
\end{tabular}

\section{Concluding remarks}

This paper proposed four kinds of hybrid bankruptcy prediction models: (1) a MDA model integrated with financial ratios, (2) a MDA model integrated with financial ratios and intellectual capital ratios, (3) a MDA-assisted neural network model integrated with financial ratios, and (4) a MDA-assisted neural network model integrated with financial ratios and intellectual capital ratios. The suggested hybrid neural network models perform very well in the bankruptcy prediction.

This study experimented MDA and hybrid neural network models using Taiwan bankruptcy data. Experimental results showed that the MDA-assisted neural network model integrated with financial ratios and intellectual capital ratios, model 4 , performs the best, which implies the potential of integrating financial ratios, intellectual capital ratios, MDA, and neural network learning.

\section{References}

[1] E.I. Altman, "Financial Ratios, Discriminant Analysis and Prediction of Corporate Bankruptcy," The Journal of Finance, 23, pp. 589-609, September 1968.

[2] E.I. Altman, R.G. Haldeman, and P. Narayana, "Zeta Analysis: A New Model to Identify Bankruptcy Risk of Corporations," Journal of Banking and Finance, pp. 29-54, June 1977.

[3] S.H. Chen and C.H. Yeh, "Toward a computable approach to the efficient market hypothesis: An application of genetic programming," Journal of Economic Dynamic \& Control," 21, pp. 1043-1063, 1997.
[4] S.H. Chen and T.W. Kuo, "Modeling International Shot-Term Capital Flow with Genetic Programming," in K. Chen, el al (eds.), Proceedings of $7^{\text {th }}$ Information Sciences (JCIS 2003), Cary, North Carolina, U.S.A., pp. 1140-1144, September 26-30, 2003.

[5] H. Chung and K. Tam, "A Comparative Analysis of Inductive-Learning Algorithm," Intelligent Systems in Accounting, Finance and Management, 2, pp. 3-18, 1992.

[6] E.B. Deakin, "A Discriminant Analysis of Predictors of Business Failure," Journal of Accounting Research, pp. 167-179, Spring 1976.

[7] H. Jo, I. Han and H. Lee, "Bankruptcy Prediction Using Case-Based Reasoning, Neural Network, and Discriminant Analysis," Expert Systems with Applications, Vol. 13 No. 2, pp. 97-108, 1997.

[8] G.V. Karels and A. Prakash, "Multivariate Normality and Forecasting of Bankruptcy," Journal of Business Finance and Accounting, pp. 573-593, Winter 1987.

[9] K.C. Lee, I. Han, and Y. Kwon, "Hybrid neural network models for bankruptcy predictions," Decision Support Systems, 18, pp. 63-72, 1996.

[10] T. Liang, J. Chandler, and I. Han, "Integrating Statistical and Inductive Learning Methods for Knowledge Acquisitions," Expert Systems with Applications, 1, pp. 391-401, 1990.

[11] J.H. Min and Y.C. Lee, "Bankruptcy prediction using support vector machine with optimal choice of kernel function parameters," Expert Systems with Applications, 28, pp. 603-614, 2005.

[12] K.S. Shin, T.S. Lee, and H.J. Kim, “An application of support vector machines in bankruptcy prediction model," Expert Systems with Applications, 28, pp. 127-135, 2005.

[13] D. West, S. Dellana, and J. Qian, "Neural network ensemble strategies for financial decision applications," Compters \& Operations Research, 32, pp. 2543-2559, 2005.

[14] G. Zhang, M.Y. Hu, B.E. Patuwo, and D.C. Indro, "Artificial neural networks in bankruptcy prediction: General framework and cross-validation analysis," European Journal of Operational Research, 116, pp. 16-32, 1999. 